\title{
Demonstration of Dose-Dependent Global and Regional Cocaine-Induced Reductions in Brain Blood Flow Using a Novel Approach to Quantitative Single Photon Emission Computerized Tomography
}

Bankole Johnson, M.D., Ph.D., Lamk Lamki, M.D., Bing Fang, M.S., Bruce Barron, M.D., Louis Wagner, Ph.D., Lynda Wells, M.D., Paul Kenny, M.D., Dennis Overton, M.D., Sukhindar Dhother, M.D., David Abramson, M.D., Richard Chen, Ph.D., and Larry Kramer, M.D.

Ischemic stroke is a common cause of morbidity and mortality in cocaine addicts. Because the previous semiquantitative single photon emission computerized tomography (SPECT) method for measuring brain blood flow does not quantify blood flow, the magnitude and specificity of cocaine's effects during drug taking has not been well established. Here, using a novel quantitative approach to SPECT, we established that intravenous cocaine administration to nine recently abstinent cocainedependent subjects was associated with significant decreases in global and regional brain blood flow to dopamine-rich areas such as the prefrontal, frontal, temporal, and subcortical gray matter. Establishing the utility of this relatively new quantitative SPECT technique provides an important tool for the management of vascular disorders of the brain. Additionally, identifying the sitespecific effects of cocaine provides targets for the development of putative therapeutic medications to attenuate or minimize ischemic stroke in cocaine addicts.

[Neuropsychopharmacology 18:377-384, 1998]

(C) 1998 American College of Neuropsychopharmacology. Published by Elsevier Science Inc.
KEY WORDS: Cocaine; Brain blood flow; SPECT; Ischemia; Stroke

Ischemic stroke is a common cause of morbidity and death in cocaine addicts (Klonoff et al. 1989; Krendel et al. 1990; Kaku and Lowenstein 1990; Miller et al. 1992).

From the Clinical Laboratory and Experimental Alcohol Research Center (BJ, RC), Division of Nuclear Medicine (LL, BF, BB, LW), Department of Anesthesiology (LW, PK, DO, SD, DA, LK), University of Texas-Health Science Center at Houston, Houston, Texas.

Address correspondence to: Bankole Johnson, M.D., Ph.D., Associate Professor and Director, Clinical Laboratory and Experimental Alcohol Research Center, University of Texas-Health Science Center at Houston, 1300 Moursund St., Houston, TX 77030. E-mail: bjohnson@msi149.msi.uth.tmc.edu

Received June 3, 1997; accepted September 11, 1997.
Localization of brain blood flow (BBF) abnormalities in cocaine users during drug taking is, however, not well characterized (Tumeh et al. 1990; London et al. 1990a,b; Woods et al. 1991; Lamki et al. 1993) but can be severe (Jensen et al. 1990; Woods et al. 1991; Holman et al. 1992). The distribution of abnormalities in perfusion vary according to whether the patient is on the drug at the time of imaging, recently withdrawn, or detoxicated for a long time (Holman et al. 1991; Strickland et al. 1991; Fowler et al. 1993; Weber et al. 1993; Volkow et al. 1996). For example, Holman and colleagues (1991) studied cocaine abusers with Tc-99m-labeled exametazime (Tc-HMPAO) and high resolution single photon emission computerized tomography (SPECT) and compared them with a group of older control subjects. Sixteen of 
18 cocaine-dependent users had abnormal perfusion characterized primarily as small focal defects involving the infraparietal, temporal, and anterofrontal cortex and basal ganglia. There was, however, no relationship between the severity of SPECT abnormalities and the mode of cocaine administration, frequency, or length of cocaine use. However, these findings of global and regional hypoperfusion are consistent with the reports of others (Mena et al. 1990; Miller et al. 1992). Pearlson and colleagues (1993) went further by suggesting that cocaine's ischemic effects on BBF were most prominent in dopamine (DA)-rich areas such as the caudate, cingulate, and frontal areas. Importantly, however, all these earlier studies examined BBF using semiquantitative SPECT. Although this method provides a useful index of regional involvement by different disease processes and pharmacological agents, it can not be used to accurately characterize changes in brain perfusion to specific brain sites.

Fortunately, it is now possible to quantify global brain perfusion by measuring brain perfusion index (BPI) directly using the recently described technique of Matsuda and colleagues (1992, 1993), the utility of which we have recently established in our laboratory (Fang et al. 1996; Lamki et al. 1997). This novel approach can also combine quantitative SPECT with BPI to obtain $\mathrm{BBF}$ for accurate quantification and characterization of cocaine's effects on regional blood flow.

Three potential problems, which have beset previous SPECT studies in cocaine-dependent individuals, were avoided in the present study. First, to ensure functional relevance, BBF acquisition was synchronized with the peak of cocaine's behavioral effects (Foltin and Fischman 1991). Second, baseline magnetic resonance imaging (MRI) was conducted to exclude subjects with gross structural brain abnormalities. Third, each subject's baseline MRI was used for more accurate anatomic correlation to map his/her region of interest (ROI) for the BBF studies. This avoids the confound of interpersonal variations in brain structure, which could result from simply drawing these ROI from anatomic estimations.

An additional advantage of this study was the use of Technetium-99-m-bicisate (Tc-ECD) instead of Tc-HM$\mathrm{PAO}$ as the radioligand for imaging. Tc-ECD, recently approved by the Food and Drug Administration (FDA) as a radioligand for imaging, may have four potential advantages over the only compound previously available, Tc-HMPAO, such as: (1) superior image quality; (2) better regional localization of BBF, particularly in areas with very low perfusion; (3) high radiochemical stability, and (4) rapid washout from extracerebral tissues (Walovitch et al. 1989; Leveille et al. 1992). These qualities of Tc-ECD make it particularly suitable for quantitatively measuring BBF in cocaine addicts during drug taking where alterations in BBF may be relatively short lived.
In this study, using recently abstinent cocaine-dependent individuals during drug taking, we demonstrated the utility of this novel quantitative approach to SPECT and used this technique to accurately characterize the effects of cocaine on BBF.

\section{MATERIALS AND METHODS}

\section{Subjects}

Nine subjects (six men and three women) between the ages of 18 and 45 years (mean $39.0 \pm 1.0$ ) who met DSM-IV (American Psychiatry Association 1994) criteria for cocaine dependence participated in this study. The Addiction Severity Index (McLellan et al. 1986) composite scores, which described the addiction-related characteristics of the nine cocaine-dependent subjects, were as follows: (1) medical: $0.026 \pm 0.026$; (2) employment/ support: $0.62 \pm 0.07$; (3) alcohol: $0.19 \pm 0.04$; (4) drug: $0.05 \pm 0.01$; (5) legal: $0.02 \pm 0.02$; (6) family/social: $0.21 \pm$ 0.04 , and (7) psychiatric: $0.04 \pm 0.02$.

\section{Screening Procedures}

Subjects were recruited by newspaper advertisement and enrolled if they: (1) met DSM-IV criteria for cocaine dependence; (2) regularly used $\geqslant 0.25 \mathrm{~g}$ of cocaine/ month and the frequency of use was less than three times per week; (3) had a history of intravenous cocaine or narcotic use; (4) weighed within $25 \%$ of ideal body weight (Metropolitan Life Tables) and were in the range of $55 \mathrm{~kg}$ to $130 \mathrm{~kg}$; (5) were in good physical health as determined by a complete physical and neurological examination, electrocardiogram within normal limits, and laboratory screening tests with no pathological significance; (6) were women and tested negative for pregnancy; (7) were willing to abide by the policies and procedures of the study; (8) had no evidence of clinically significant gross structural brain abnormality on a baseline MRI that was inspected by a physician specialisteach subject's MRI data were also used to anatomically map ROIs on his/her own SPECT scans; and (9) provided written informed consent. This study received ethics approval by the Committee for the Protection of Human Subjects, University of Texas-Health Science Center at Houston.

\section{Study Procedures}

After screening, subjects were familiarized with the test conditions, and a baseline MRI was conducted within the week. Prior to each test day, subjects resided overnight at the University Clinical Research Center (UCRC) and were only tested the next morning if they were drug-free on urinalysis and had a breath alcohol reading of zero. Voiding or urine was supervised by clinical 
staff. Subjects experienced the following treatment conditions on three separate test days, each punctuated by a rest period of 7 to 21 days, in double-blind, randomized, cross-over fashion: (1) placebo, (2) low-dose cocaine (i.e., $0.325 \mathrm{mg} / \mathrm{kg} \mathrm{IV}$ ), or (3) high-dose cocaine $(0.650 \mathrm{mg} / \mathrm{kg} \mathrm{IV})$. As a safety precaution, we planned to terminate subject testing if his/her cardiovascular parameters exceeded the following values during the experiment: systolic $\mathrm{BP}>210 \mathrm{~mm} \mathrm{Hg}$, diastolic $\mathrm{BP}>130$ $\mathrm{mm} \mathrm{Hg}$, pulse $>185 / \mathrm{min}$ or $(230-$ subject age $\times 0.85$ per min), or oxygen tension $\left(\mathrm{PaO}_{2}\right)<94 \%$. No such incident occurred.

On each test day, at 07:30 $\mathrm{h}$, subjects received their baseline vital signs measurements. At 07:45 h, a 20G intravenous cannula was inserted into an arm vein, by an anesthesiologist who also supervised all subsequent intravenous drug administrations and cardiovascular monitoring (see below). During the experiment, the cannula was kept patent by injection of $2-5 \mathrm{ml}$ of a weak heparinized saline solution and the infusion of 80 $\mathrm{ml} / \mathrm{h}$ of $0.9 \% \mathrm{w} / \mathrm{v}$ saline for the duration of the experiment (i.e., $240 \mathrm{ml}$ of fluid between 08:00 $\mathrm{h}$ and 11:00 h). This saline infusion also served to keep the subject well hydrated during the experiment. Cardiovascular function (i.e., EKG, BP, pulse, and oxygen tension) was monitored continuously during the session using peripheral sensors connected to the automated Escort 300 Patient Monitor (E300PM; Medical Data Electronics ${ }^{\mathrm{TM}}$ ). These sensors were attached on the arm opposite to the cannulation site. Vein cannulation and the attachment of peripheral sensors for the E300PM device was completed by 08:00 $\mathrm{h}$.

At $08: 30 \mathrm{~h}$, cocaine $(0.325$ or $0.650 \mathrm{mg} / \mathrm{kg} \mathrm{IV})$ or placebo was administered over $60 \mathrm{~s}$ via a Baxter Infus O.R. ${ }^{\mathrm{TM}}$ Pump, an automated infusion delivery pump. At $08: 35 \mathrm{~h}$, radioactive tracer (Tc-ECD) was delivered as a tight intravenous bolus followed by immediate dynamic acquisition and quantification of BPI. Acquisition of blood flow measurements took $5 \mathrm{~min}$. BBF measurements were thus scheduled to occur within the peak of cocaine's behavioral effects (Foltin and Fischman 1991). At 09:10 $h$, the SPECT images were acquired for regional quantification. At 11:00 h, continuous cardiovascular monitoring was discontinued by disconnection of the E300PM device, the saline infusion was terminated, and lunch was provided. At 12:00 h, subjects received a final cardiovascular check by the attending anesthesiologist and were discharged.

\section{Technique}

Acquisition of Global Brain Blood Flow Data. Brain SPECT imaging was carried out using $15 \mathrm{mCi}$ Tc-ECD. Subjects were injected under controlled conditions with eyes opened in a quiet, semi-darkened room with just a small lamp for background light. The dose was injected intravenously only after the subject had recovered from the discomfort of establishing an intravenous line. During the injection, a dynamic rapid sequence blood flow acquisition was undertaken using a dual head large field-of-view Gamma Camera (BIAD, Trionix). The subject was positioned in the long axis of the large field-ofview camera, so that the aorta and the head could both be recorded simultaneously. The passage of the bolus from the aorta to the brain acted as the input function, for quantitative calculations of blood flow to the brain. Time activity curves were derived from this first pass study by drawing ROI over the left and right hemispheres and also over the aortic arch (input function). From this, a BPI was calculated as per the method of Matsuda and colleagues (1992), who showed that BPI is representative of global blood flow. After the injection, a sequence of 110 frames were acquired at 1-s intervals, using a $128 \times 128$ matrix, with the subject supine, and anterior view acquisition.

Calculation of BPI. The analysis was based on the theory of a unidirectional transfer process, whereby brain radioactivity, as a function of time, $B(t)$, was expressed as:

$$
B(t)=K u \int_{0}^{\mathrm{t}} A(\tau) d \tau+V n A(\mathrm{t})
$$

where $A(\mathrm{t})$ is the arterial activity as a function of measurement time $(t), \tau$ is time, $K u$ is the unidirectional influx rate, $V n$ is the initial distribution volume for the tracer, which is the space of exchangeable region plus the plasma space.

For quantitative analysis of hemispheric brain perfusion (hemispheric), ROI were drawn over the aortic arch $\left(\mathrm{ROI}_{\text {aorta }}\right)$ and bilaterally over the brain hemispheres $\left(\mathrm{ROI}_{\text {brain }}\right)$ as per Matsuda and colleagues (1992). The ratios of the ROI were approximately 55 pixels for the aorta and about 300 pixels for each cerebral hemisphere. Using aortic activity minimized the invasiveness of the procedure, instead of using arterial activity from blood samples. The time-activity curves of the ROI were processed with a smoothing technique modified from Matsuda and colleagues (1992), and the two curves were then corrected by shifting the brain activity curve to the left so that the aorta and brain time-activity curves overlapped at the peak times (curves matched). A graphically obtained slope $(K u)$ was then obtained, and when this was multiplied by the ratio of the two ROI areas and a constant we obtained the BPI: BPI = $100 \mathrm{Ku} 10$ (ROI $\mathrm{Rorta}_{\text {size }) /(\mathrm{ROI}}$ brain size). In the calculation of the BPI, $K u$ representing the unidirectional influx constant and its intercept with the Y-axis (the initial volume of distribution, $V n$ ), were used for correction together with ROI.

Acquisition of Brain SPECT Images. After the acquisition of the dynamic blood flow study described for 
Table 1A. Mean Global Blood Flow Assessments in Nine Cocaine-Dependent Subjects After the Administration of Placebo, Low-Dose Cocaine $(0.325 \mathrm{mg} / \mathrm{kg}$ IV), and High-Dose Cocaine $(0.650 \mathrm{mg} / \mathrm{kg}$ IV)

\begin{tabular}{lccc}
\hline Placebo & $\begin{array}{c}\text { Low-Dose } \\
\text { Cocaine } \\
(\boldsymbol{n}=\mathbf{9})\end{array}$ & $\begin{array}{c}\text { High-Dose } \\
\text { Cocaine } \\
(\boldsymbol{n}=\mathbf{9})\end{array}$ \\
\hline BPI & $12.77 \pm 1.39$ & $11.33 \pm 1.07 ; \mathrm{b}^{* *}$ & $10.77 \pm 1.21 ; \mathrm{a}^{* *}, \mathrm{c}^{*}$ \\
WBBF & $52.88 \pm 3.85$ & $48.83 \pm 3.22 ; \mathrm{b}^{* *}$ & $47.27 \pm 3.32 ; \mathrm{a}^{* *}, \mathrm{c}^{*}$ \\
\hline
\end{tabular}

$\mathrm{a}=$ comparisons between high-dose cocaine and placebo; $\mathrm{b}=\mathrm{com}$ parisons between low-dose cocaine and placebo; $c=$ comparisons between high-dose cocaine and low-dose cocaine.

BPI was used to calculate whole brain blood flow (WBBF) as described by Matsuda and colleagues (1992).

WBBF was measured in $\mathrm{ml} / 100 \mathrm{~g} / \mathrm{min}$.

${ }^{*} p<.05$.

$* * p \leqslant .01$.

BPI, a regular static brain SPECT was then acquired (approximately $40 \mathrm{~min}$ post-cocaine injection) using a 3-headed Gamma Camera (TRIAD, Trionix), with a fan beam collimator. We used a $256 \times 128$ matrix and $10 \mathrm{~s} /$ stop for 120 stops at 3 degrees/stop (total 360 degrees rotation). Reconstruction of the raw images was under- taken after re-binning of the data using a $128 \times 128$ matrix with slice kernel of 5, namely, 12521 . A Butterworth prefilter was used with a high frequency cut-off of $0.75 \mathrm{cyc} / \mathrm{cm}$, Nyquist of $2.809 \mathrm{cyc} / \mathrm{cm}$ and roll off degree (alpha) at 7.0, followed by a Ramp filter. The three planar slices obtained from this volumetric acquisition: transaxial, coronal, and sagittal slices were qualitatively analyzed for regional blood flow. Images were evaluated routinely for motion artifacts, using a cine presentation of the raw projection images as well as a sinogram for vertical and lateral motion. If there was motion, the acquisition was repeated immediately without the necessity of reinjection.

Calculation of Regional BBF. Because the baseline MRI and SPECT images were acquired in the same anteriorposterior tilt to the orbitomeatal line, regional slices were easily comparable and superimposed. This procedure allowed the use of MRI to fit anatomic designations for each brain SPECT slice in each subject, thus correcting for possible interindividual differences in brain structure. The 20 ROIs for each hemisphere used in this study were a modification of those described by Ebert and colleagues (1996). Superimposition of MRI

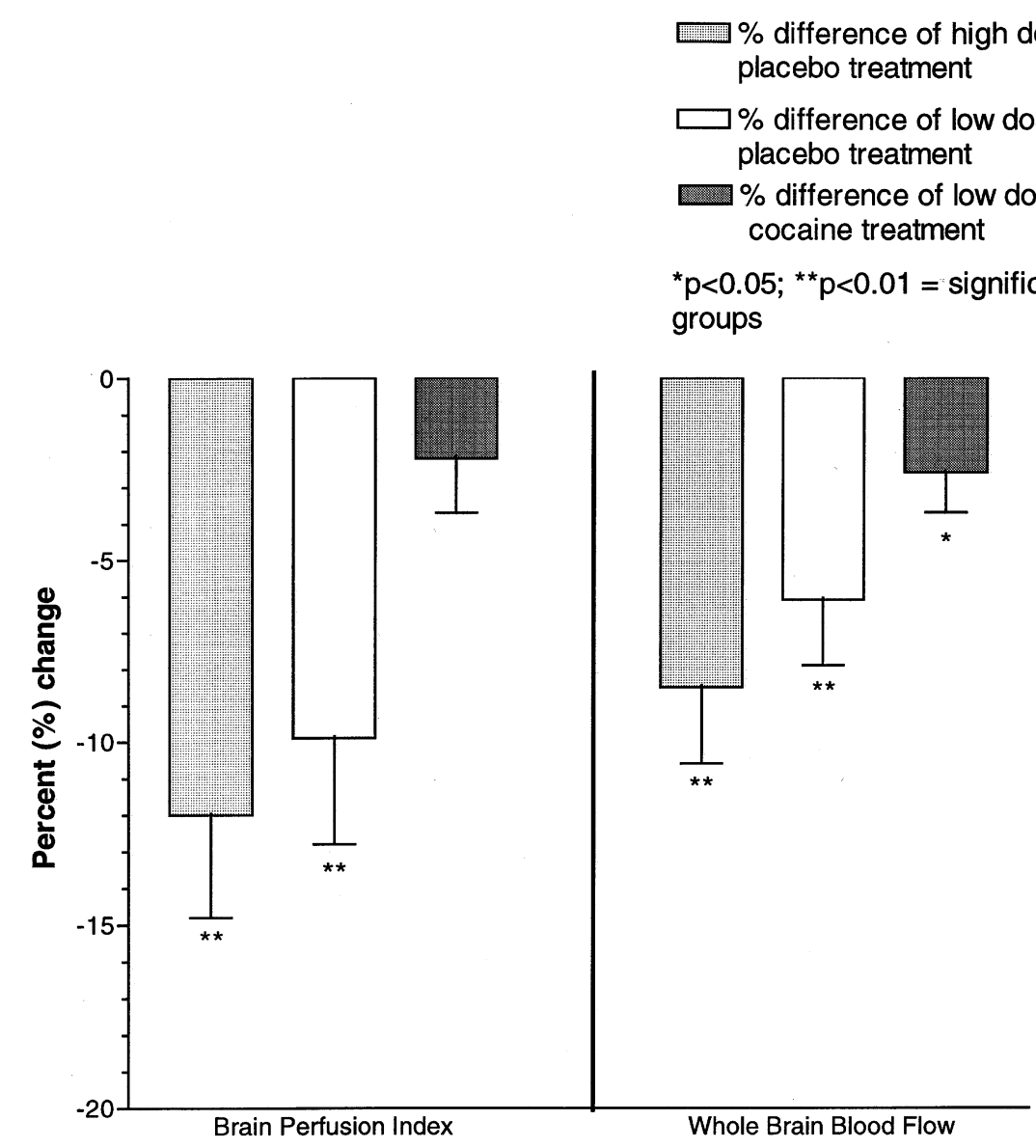

Figure 1A. Mean percent change in global blood flow assessments in nine cocaine-dependent subjects following the administration of placebo, low-dose cocaine $(0.325 \mathrm{mg} / \mathrm{kg}$ IV), and high-dose cocaine $(0.650 \mathrm{mg} / \mathrm{kg} \mathrm{IV)}$. 
Table 1B. Mean Absolute Regional Blood Flow (ml/100 g/min) Assessments in Nine Cocaine-Dependent Subjects After the Administration of Placebo, Low-Dose Cocaine (0.325 $\mathrm{mg} / \mathrm{kg} \mathrm{IV})$ and High-Dose Cocaine $(0.650 \mathrm{mg} / \mathrm{kg}$ IV)

\begin{tabular}{lccc}
\hline ROI* & Placebo $(\boldsymbol{n}=\mathbf{9})$ & Low-Dose Cocaine $(\boldsymbol{n}=\mathbf{9 )}$ & High-Dose Cocaine $(\boldsymbol{n}=\mathbf{9})$ \\
\hline Prefrontal (SF1) & $64.22 \pm 6.03$ & $61.05 \pm 6.02$ & $57.44 \pm 5.11 ; \mathrm{a}^{* *}$ \\
Prefrontal (SF2) & $62.88 \pm 6.18$ & $55.66 \pm 4.16 ; \mathrm{b}^{*}$ & $52.66 \pm 4.90 ; \mathrm{a}^{* *}$ \\
Prefrontal (SF3) & $56.38 \pm 5.35$ & $52.77 \pm 4.33$ & $49.94 \pm 4.16 ; \mathrm{a}^{*}$ \\
Medial frontal & $61.94 \pm 5.94$ & $61.27 \pm 5.72$ & $55.83 \pm 5.97 ; \mathrm{a}^{* *}$ \\
Inferior frontal & $58.44 \pm 5.15$ & $54.66 \pm 4.00$ & $54.61 \pm 4.92 ; \mathrm{a}^{* *}$ \\
Central parietal 1 & $70.38 \pm 8.14$ & $65.50 \pm 5.82$ & $65.77 \pm 6.11$ \\
Central parietal 2 & $61.77 \pm 6.11$ & $58.55 \pm 4.81$ & $58.44 \pm 5.45$ \\
Superior parietal & $66.50 \pm 6.88$ & $64.05 \pm 6.56$ & $66.66 \pm 7.88$ \\
Inferior parietal & $62.38 \pm 4.46$ & $56.55 \pm 4.61 ; \mathrm{b}^{* *}$ & $59.22 \pm 6.03$ \\
Superior occipital & $72.27 \pm 7.37$ & $66.72 \pm 5.76$ & $67.05 \pm 5.90$ \\
Inferior occipital & $69.38 \pm 4.99$ & $65.72 \pm 6.39$ & $67.33 \pm 6.73$ \\
Superior temporal & $64.38 \pm 5.27$ & $58.05 \pm 4.36 ; \mathrm{b}^{* *}$ & $57.77 \pm 5.02 ; \mathrm{a}^{* *}$ \\
Lateral temporal & $50.11 \pm 4.28$ & $48.05 \pm 3.70$ & $44.55 \pm 3.53 ; \mathrm{a}^{*}, \mathrm{c}^{*}$ \\
Medial temporal & $41.77 \pm 3.30$ & $40.61 \pm 2.93$ & $37.66 \pm 1.74$ \\
Inferior temporal & $40.88 \pm 3.00$ & $38.05 \pm 3.06$ & $37.77 \pm 3.12$ \\
Caudate & $77.22 \pm 7.28$ & $68.05 \pm 5.67$ & $64.00 \pm 5.27 ; \mathrm{a}^{* *}$ \\
Putamen & $85.61 \pm 9.31$ & $71.27 \pm 4.57 ; \mathrm{b}^{*}$ & $71.22 \pm 5.82 ; \mathrm{a}^{* *}$ \\
Thalamus & $78.61 \pm 9.14$ & $69.50 \pm 5.47$ & $64.61 \pm 5.82 ; \mathrm{a}^{* *}$ \\
Cingulate & $62.83 \pm 6.08$ & $63.00 \pm 6.88$ & $57.27 \pm 3.84$ \\
Cerebellum & $80.22 \pm 7.59$ & $75.11 \pm 6.76$ & $78.66 \pm 7.04$ \\
\hline
\end{tabular}

$\mathrm{a}=$ comparisons between high-dose cocaine and placebo; $\mathrm{b}=$ comparisons between low-dose cocaine and placebo; $\mathrm{c}=$ comparisons between high-dose cocaine and low-dose cocaine.

$* p<.05$.

$* * \leqslant .01$.

and SPECT scans, and the drawing of ROIs were conducted electronically using proprietary software. Prior to the ROI analyses, the images were qualitatively reviewed for uniformity of activity distribution throughout the gray matter of the brain. To calculate the quantitative regional localization of BBF (Matsuda et al. 1993) and to correct for incomplete regions of TC-ECD in the brain, Lassen and colleague's (1988) linearization algorithm of a curve-linear relationship between brain activity and blood flow was applied: $\mathrm{Fi}=\operatorname{Fr} \times \alpha\left(\mathrm{C}_{\mathrm{i}} / \mathrm{C}_{\mathrm{r}}\right) /[1+$ $\alpha-\left(C_{i} C_{r}\right)$ ] where $F_{i}$ and $F_{r}$ represented combined blood values for a region $I$ and a reference region $r ; C_{i}$ and $C_{r}$ were the SPECT counts for the region I and the reference region $r$ respectively, $\alpha$ was the correction factor for linearization. Thus regional blood flow was calculated from the SPECT slices, and the BPI as suggested by the method of Matsuda and colleagues (1992).

\section{Statistical Analyses}

All data were analyzed by computer using SAS ${ }^{\mathrm{TM}}$ (SAS Institute 1992). Subjects served as their own controls to minimize interindividual differences in BBF measurements. Data were summarized as their mean \pm standard error (SE). Differences between treatment conditions (placebo, low-dose cocaine, and high-dose cocaine) were compared using paired $t$-tests.

\section{RESULTS}

From Table 1A and Figure 1A, it can be seen that compared with placebo, both low and high-dose cocaine taking were associated with significant reductions in global $\mathrm{BBF}$, the greater effect being at the higher cocaine dose.

From Table 1B and Figure 1B, it can be seen that cocaine taking produced dose-dependent reductions in regional $\mathrm{BBF}$, predominantly to DA-rich regions such as the prefrontal cortex (SF1, SF2), frontal cortex, temporal lobe, and subcortical gray matter. Interestingly, brain regions with comparatively little DA innervation (e.g., inferior occipital) showed statistically insignificant changes. No between hemispheric differences were seen (data not shown).

\section{DISCUSSION}

Accurate characterization and localization of cocaine's effects on BBF are an important prerequisite to understanding the mechanism by which it produces ischemic stroke. This study, which demonstrated the utility of Matsuda and colleagues' $(1992,1993)$ technique for quantification of blood flow, showed that cocaine taking was associated with global reductions in BBF as 


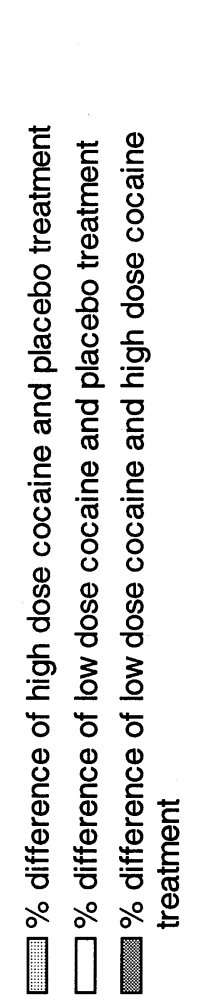

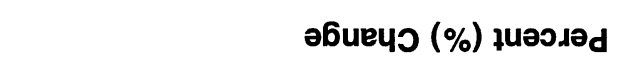

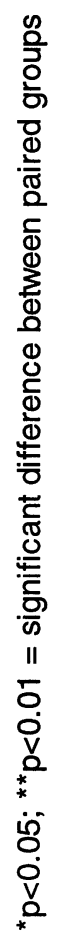
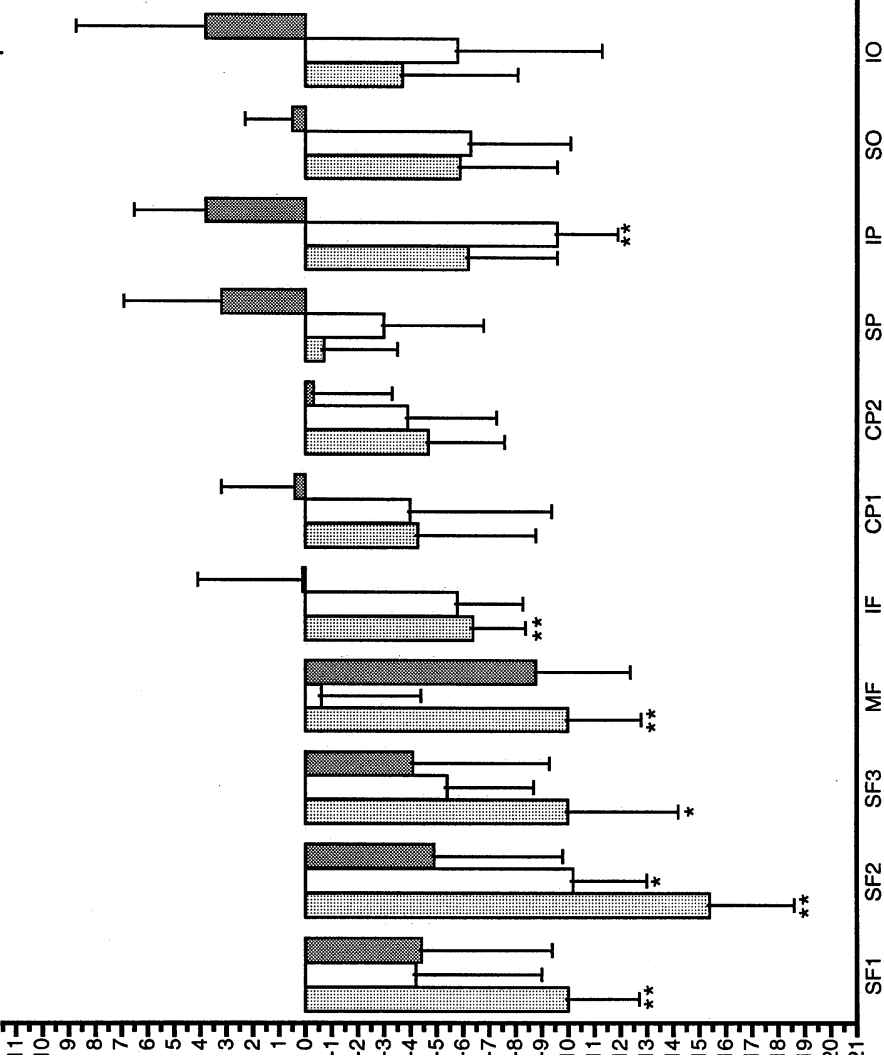

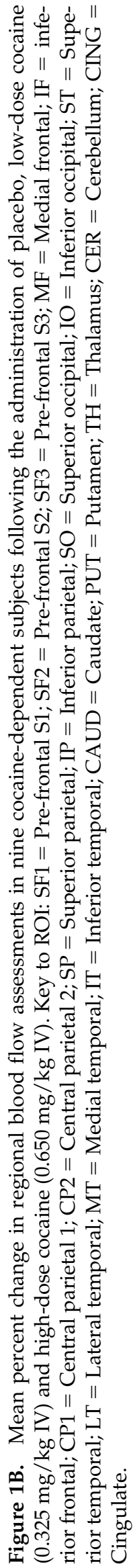


measured by the BPI method (Table 1A). Interestingly, however, these blood flow reductions after cocaine were most marked in DA-rich brain regions (e.g., prefrontal, frontal, temporal, and subcortical gray matter), sites that have been associated with the predominant pharmacological and behavioral effects of cocaine (Hemby et al. 1997). Whereas the largest reductions in regional blood flow to these DA-rich areas were usually associated with the higher dose of cocaine (Table 1B), this was not a simple linear relationship. For example, some areas (e.g., inferior parietal) showed BBF decreases at the low but not the high dose, while other regions (e.g. superior temporal) had no significant additional reductions at the higher dose. Since vasospasm may accentuate DA-related brain ischemia (Holman et al. 1993), disproportionate effects between these two mechanisms may explain the nonlinearity of cocaine's effects in these regions. A similar postulate was advanced by Volkow and colleagues (1992) who attributed the smaller reductions in blood flow compared with the basal ganglia to predominance of vasospasm cortically and blockade of DA in the mid-brain. In any case, these results suggest that DA mechanisms are important to the expression or may be a consequence of cocaine-induced ischemia, and medications targeted at opposing cocaine's activity at these DA sites may reduce its ischemic effects.

Enhanced methodological strategies were used to ensure subject safety and data reliability during the BBF studies in cocaine addicts in this experiment. These included: (1) rigorous screening of health status including extensive monitoring of cardiovascular parameters during the study, (2) utilization of a baseline MRI to exclude subjects with gross structural brain abnormalities and to help map ROI, (3) the use of Tc-ECD as the radioligand for conducting such low-flow perfusion studies, (4) synchronizing BBF acquisition with the peak of cocaine's behavioral effects, and (5) demonstrating that studies using similar procedures can be conducted safely in humans.

Finally, it occurred to us that this study's safety and reproducibility may have wider implications. For example, this paradigm could serve as a useful human model with which to study brain ischemia in general, as this too appears to involve DA mechanisms (Nakane et al. 1995). Candidate medications for the management of ischemic strokes irrespective of etiology may, therefore, also be effective treatments for the attenuation of cocaine-induced cerebrovascular accidents and should be studied for both these indications.

\section{ACKNOWLEDGMENTS}

We would like to thank the staff at the CLEAR Center, UCRC, and the Departments of Nuclear Medicine and Anesthesiology for assistance. We are grateful for funding of this project by the Advanced Technology Program of Texas \# 011618-006 and NIH grant \# M01-RR02558. Tc-ECD was kindly supplied by Du Pont Pharma.

\section{REFERENCES}

American Psychiatric Association (1994): Diagnostic and Statistical Manual of Mental Disorders-IV, 4th ed. Washington, DC, American Psychiatric Association

Ebert D, Feistel H, Lowe T, Pirner A (1996): Dopamine and depression-Striatal dopamine $\mathrm{D}_{2}$ receptor SPECT before and after antidepressant therapy. Psychopharmacology 126:91-94

Fang B, Lamki L, Barron B, Williams T, Johnson B, Wagner LK (1996): Problems encountered in quantification of brain perfusion index (BPI) derived from brain flow acquisition with TC-HMPAO and TC-ECD. Presented at the Annual Meeting of the Southwestern Chapter of the Society of Nuclear Medicine. Clin Nucl Med 21(2):169

Foltin RW, Fischman MW (1991): Smoked and intravenous cocaine in humans: Acute tolerance, cardiovascular and subjective effects. J Pharmacol and Exp Ther 257(1):247261

Fowler JS, Wang GJ, Hitzemann AP, Wolf JL, Logan J, Schlyer D, MacGregor RR, Angrist B, Lieberman J, Burr G, Pappas N (1993): PET studies of the function of the dopamine transporter in cocaine abusers. J Nucl Med 34:102P

Hemby SE, Johnson BA, Dworkin SI (1997): Neurobiological basis of drug reinforcement. In Johnson BA, Roache J (eds), Drug Addiction and Its Treatment: Nexus of Neuroscience and Behavior. New York, Lippincott-Raven, pp 137-169

Holman BL, Mendelson J, Garada B, Teoh SK, Hallgring E (1993): Regional cerebral blood flow improves with treatment in chronic cocaine polydrug users. J Nucl Med 34:723-727

Holman BL, Garada B, Johnson KA, Mendelson J, Hallgring E, Teoh SK, Worth J, Navia B (1992): A comparison of brain perfusion SPECT in cocaine abuse and AIDS dementia complex. J Nucl Med 33:1312-1325

Holman BL, Carvalho PA, Mendelson J, Teoh SK, Nardin R, Hallgring E, Hebben N, Johnson KA (1991): Brain perfusion is abnormal in cocaine-dependent polydrug users: A study using technetium-99m-HMPAO and ASPECT. J Nucl Med 32:1206-1210

Jensen R, Olsen TS, Winther BB (1990): Severe non-occulsive ischemic stroke in young heroin addicts. Acta Neurol Scand 81:354-357

Kaku DA, Lowenstein DH (1990): Emergence of recreational drug abuse as a major risk factor for stroke in young adults. Ann Intern Med 113:821-827

Klonoff DC, Andrews BT, Obana WG (1989): Stroke associated with cocaine use. Arch Neurol 46:989-993

Krendel DA, Ditter SM, Frankel MD, Ross WK (1990): Neurology 40:1092-1094

Lamki L, Johnson B, Simms D, Fang B, Barron B, Wagner L, Bordnick P, Chen R, Meisch R, Vogelson L, Maugans W, Overton D (1997): Cocaine-Related Changes in Brain 
Blood Flow. Presented at the $59^{\text {th }}$ Annual College on Problems of Drug Dependence Meeting, Nashville, TN

Lamki LM, Tran HD, Barron BJ (1993): A gamut of pitfalls and artifacts in high resolution Tc-99m-Exametazime brain SPECT imaging and some solutions. Clin Nucl Med 18:174

Lassen NA, Andersen AR, Friberg L, Paulson OB (1988): The retention of [99mTc]-d,l-HM-PAO in the human brain after intracarotoid bolus injection: A kinetic analysis. J Cereb Blood Flow Metab 8(6):S13-22

Levant B, Grigoriadis DE, DeSouza EB (1995): Relative affinities of dopaminergic drugs at dopmaine D2 and D3 receptors. Eur J Pharmacol 278:243-247

Leveille J, Demonceau G, Walovitch RC (1992): Intrasubject comparison between technetium-99m-ECD and technetium-99m-HMPAO in healthy human subjects. J Nucl Med 33:480-484

London ED, Broussolle EPM, Links JM, Wong DF, Cascella NG, Dannals RF, Sano M, Herning R, Snyder FR, Rippetoe LR, Toung TJK, Jaffe JH, Wagner H (1990a): Morphine-induced metabolic changes in human brain. Arch Gen Psych 47:73-86

London ED, Cascella NG, Wong DF, Phillips RL, Dannals RF, Links JM, Herning R, Grayson R, Jaffe JH, Wagner HN Jr (1990b): Cocaine-induced reduction of glucose utilization in the human brain. Arch Gen Psychiatry 47:567-574

Matsuda H, Tsuji S, Shuke N, Sumiya H, Tonami N, Hisada K (1993): Noninvasive measurements of regional cerebral blood flow using technetinum-99m hexamethylprophylene amine oxine. Eur J Nucl Med 20:391-401

Matsuda H, Tsuji S, Shuke N, Sumiya H, Tonami N, Hisada K (1992): A quantitative approach to technetium-99m hexamethylpropylene amino oxine. Eur J Nucl Med 19:195-200

McLellan AT, Luborsky L, Cacciola J, Griffiths J, Evans F, Barr H, O'Brien C (1986): New data from the addiction severity index: reliability and validity scores from three centres. J Nerv Ment Dis 173:412-423

Mena I, Giombetti R, Moody CK, Villanueva-Meyer J, Garrett K, Mendoza R, Miller B (1990): Acute cerebral blood flow changes with cocaine intoxication. Neurology 40 (Suppl. 1):179

Miller BL, Mena I, Giombetti R, Villanueva-Meyer J, Djen- deredjian AH (1992): Neuropsychiatric effects of cocaine. J Addict Dis 11:47-58

Nakane H, Ooboshi H, Ibayashi S, Yao H, Sadoshima S, Fujishima M (1995): Isradipine, a calcium channel blocker, attenuates the ischemia-induced release of dopamine but not glutamate in rats. Neurosci Lett 188:151-154

Pearlson GD, Petra JJ, Harris GJ, Ross Christopher RA, Fischman MW, Camargo EE (1993): Correlation of acute cocaine-induced changes in local cerebral blood flow with subjective effects. Am J Psychiatry 150:495-497

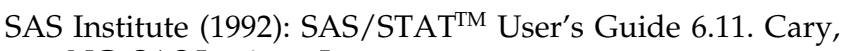
NC, SAS Institute Inc.

Strickland A, Mena I, Villanueva-Meyer J, Tabbarah B, Miller B (1991): Long-term effects of cocaine abuse on brain perfusion: assessment with XE-133 rCBF and Tc99m-HMPAO. J Nucl Med 32:1021-1022 [abstract]

Tumeh SS, Nagel JS, English RJ, Moore M, Holman BL (1990): Cerebral abnormalities in cocaine abusers: Demonstration by SPECT perfusion brain scintigraphy. Radiology 176:821-824

Volkow ND, Wang GJ, Fowler JS, Logan J, Hitzemann R, Gatley SJ, MacGregor RR, Wolf AP (1996): Cocaine uptake is decreased in the brain of detoxified cocaine abusers. Neuropsychopharmacology 14:159-168

Volkow ND, Fowler JS, Wang G-J, Hitezeman R, MacGregor R, Logan J, Dewey S, Wolf AP (1992): Brain dopamine changes in cocaine abusers. J Nucl Med 33:887 [abstract]

Walovitch RC, Hill TC, Garrity ST, Cheesman EH, Burgess BA, O'Leary DH, Watson AD, Ganey MV, Morgan RA, Williams SJ (1989): Characterization of technetium-99mL,L-ECD for brain perfusion imaging. Part 1: Pharmacology of technetium-99m ECD in nonhuman primates. J Nucl Med 30:1892-1901

Weber DA, Franceschi D, Ivanovic M, Atkins HL, Cabahug C, Wong CTC, Susskind H (1993): SPECT and planar brain imaging in crack abuse: Iodine-123-iodoamphetamine uptake and localization. J Nucl Med 34:899-907

Woods SW, O'Malley SS, Martini BL, McDougle CJ, Price LH, Krystal JH, Hoffer PB, Kosten TR (1991): SPECT regional cerebral blood flow and neuropsychological testing in non-demented HIV-positive drug abusers: Preliminary results (Tc-HMPAO). Prog Neuropsychopharmacol Biol Psychiatry 15:649-662 